patients with the disease show little indication of having prognostic significance (S. A. Goldblatt and E. M. Nadel). The articles on therapy are concerned with various ways in which a tumour may be destroyed without irreparable damage to the host. They range over considerations of how radiotherapy may be made more specific, the ways in which bone marrow may be regrafted, to the use of regional perfusion of cancer chemotherapeutic agents.

This book is well written and produced throughout and will be read with profit both by experimentalists and those concerned with the human cancer patient. The wide range of specialist articles which it contains will make it a candidate for the library rather than for the individual bookshelf.

D. B. Clayson

\section{LIPIDS AND LEUCODYSTROPHIES}

Brain Lipids and Lipoproteins, and the Leucodystrophies

Proceedings of the Symposium held in Rome, 1961, Organized by the World Federation of Neurology. Edited by Prof. J. Folch-Pi and Prof. H. Bauer. Pp. 213. (Amsterdam, London and New York: Elsevier Publishing Company, 1963.) n.p.

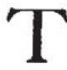
HE sub-divisions of biochemistry seem to increase yearly. Not so long ago the idea of 'neurochemistry' as an important branch of biochemistry was a novel one; in 1963 the neurochemist specializing in the lipids of the brain might well consider himself a stranger to the proteins of the same organ.

The present volume is concerned with the biochemistry of brain lipids but at least half the text is concerned with the relation of certain lipids to the leucodystrophies. These are rare neurolipodoses, which, to quote the preface, "represent a heterogeneous group of disorders, some of which clearly show a genetic pattern and abnormalities of white substance arising from a disturbance in the dynamic biochemistry of lipids and lipoproteins". Neuropathologists have been intrigued by these disorders for many years. Emphasis on their clinical aspects in this book is, therefore, to be expected since it consists of the proceedings of a symposium organized by the Problem Commission of Neurochemistry of the World Federstion of Neurology. If the prospective reader is at first put off by the sight of yet another collection of symposium papers, he may rest assured that the quality of many of the contributions is considerable.

There are a number of papers on the interactions of lipids and proteins (particularly those in proteolipids) and the relationship of these complexes to classical neurokeratin. Much more is known about the nature of the lipid components than the proteins but their structural relationships in, for example, the precise geometrical arrangement of the myelin sheath are of paramount importance. The portion of the book covering these problems will appeal to lipid biochemists in general.

The second half of the book makes more difficult, if none the less interesting, reading. The classification of the leucodystrophies is baffling and some of the histochemical observations have made confusion worse confounded. A newcomer to the field must familiarize himsolf with varieties of leucodystrophy like 'metachromatic', 'sudanophilic' and 'globoid cell'. It is good to know, therefore, that a start has been made in classifying these diseases in biochemical terms. Thus, infantile metachromatic leucodystrophy is now known to be a special type of sphingolipidosis, namely, a sulphatide lipidosis. In this disease, sulphatides accumulate in the white matter of the brain and, as Austin and Hagberg have shown, they are excreted in the urine, thereby yielding a diagnostic test. Such an advance has been possible only because of improved techniques in lipid analysis and, in the contribution from Svennerholm, very detailed analyses are given of the brain lipids in leucodystrophies. One of his interesting observations is that brain sphingomyelins in such cases may nover acquire the fatty acid pattern characteristic of the mature organ. This would imply a biochemical lesion in the anabolism of complex lipids which is almost certainly genetically determined. It is also possible that an understanding of the metabolic disturbance in diseases of this type might assist in understanding the ætiology of more commonly occurring demyelinating diseases like multiple sclerosis.

Genorally speaking, the book is well producod on paper of high quality. It has an apparently adequate author index, but the subject index leaves something to be desired; it contains, for example, only one reference to 'sphingomyelin' whereas this lipid is mentioned in several different parts of the text. On balance, this book will bo of groat interest to neurochemists, lipid chemists and those clinicians interested in the scientific basis of neurological disorders.

G. B. Ansell

\section{INTRODUCTION TO BIOCHEMISTRY}

Outlines of Biochemistry

By Prof. Eric E. Conn and Prof. P. K. Stumpf. Pp. viii +391. (New York and London: John Wiley and Sons, Inc., 1963.) 658.

FOR many years biochemistry was regarded as a F borderline subject between chemistry and biology; as such it tended to be neglected by both. The explosive increase in biochemical knowledge since the introduction of radioactive isotopes has forced the realization that a knowledge of biochemical methods and biochemical philosophy is an essential part of the educational equip. ment of all biologists. University teachers and even school teachers are faced, therefore, with a major problem. They must familiarize themselves with a subject which is growing at a formidable rate and they must, in addition, select from a mass of detail those aspects of biochemistry which will convey to the student a coherent picture of the chemical basis of life.

In the present volume, the authors have essayed to provide an introductory course which can be covered, according to their somewhat optimistic estimate, in one semester. Surely this must be one of the most difficult tasks which can be undertaken by any teacher, and it is a measure of the quality of their presentation that the authors have not entirely failed. There are brief and clearly written sections covering the fundamental concepts of chemistry and the detailed chemistry of the major cell components. This is followed by a fairly detailed account of intermediary metabolism which occupies much of the book. There is finally a brief account of some of the techniques used in biochemical research. At all times, the presentation is admirably concise, clear and free from errors and the book could be used with confidence by any teacher. I am not convinced, however, that it could be recommended with equal confidence to the student for his own use. An introductory book should do more than present established facts; it should give the beginner a clear idea of the way in which these facts were established. In some sections of the book, for example, that on anaerobic carbohydrate metabolism, the authors have succeeded in bringing their subject to life, but in general one would have preferred to see greater emphasis on methods. The dominant part played in biochemical research by analytical methods, by enzyme purification, by isotopes, and by the centrifuge is not brought out. One must admit, however, that the task which the authors have set themselves is an almost impossible one, and that they have even partially succeeded in their endeavour is a compliment to their ability as teachers.

The book is beautifully printed and produced but is expensive as an introductory text. $\quad$ T. S. Work 